\title{
INOVANDO A ATIVIDADE DE PISCICULTURA AMAZÔNICA
}

\author{
Innovating the Amazon's Fish-Farming Activity
}

\section{RESUMO}

Este trabalho trata sobre a inovação com foco na estratégica competitiva para a produção de peixes em cativeiro na Amazônica. $\mathrm{O}$ pressuposto está no eixo da análise sistêmica de contingências visando à redução de custos operacionais e ganho de competitividade. Tem base na Teoria Contingencial segundo a perspectiva de Joan Woodward. A problematização é: como se caracteriza a inovação com sustentabilidade para a excelência competitiva da piscicultura Amazônica? Empregou-se Método de Estudo de Caso, com abordagem quali-quantitativa; envolveu consulta a especialistas e grupo focal. Como resultado concluiu-se que a inovação caracterizase pelo rompimento da tradição que perpetua práticas improdutivas ou de alto impacto. Recomenda-se que esses idealizadores sejam internalizados nas políticas dos órgãos de fomento. Este estudo servirá para reflexão entre os interessados na elaboração de políticas públicas para o desenvolvimento local integrado e gestores que pretendem formular estratégias competitivas na piscicultura sustentável.

Alexandre Leonardo Simões Piacentini

Universidade Federal de Rondônia

alexandre.piacentini@gmail.com

Flávio de São Pedro Filho

Universidade Federal de Rondônia

flavio1954@gmail.com

Maria José Aguilar Madeira

Universidade da Beira Interio

maria.jose.madeira@ubi.pt

Elvino Ferreira

Universidade Federal de Rondônia

elvino@unir.br

Marcos Tadeu Simões Piacentini

Universidade Federal de Rondônia

marcos.piacentini@gmail.com

Recebido em: 30/09/2017. Aprovado em: 06/02/2020.

Avaliado pelo sistema double blind review

Avaliador científico: Elisa Reis Guimarães

\begin{abstract}
This paper concerns innovation with a focus on competitive strategy in fish production in the Amazon. The assumption is the axis of the systemic analysis of contingencies in order to reduce operating costs and gain competitiveness. It is based on Contingency Theory from the perspective of Joan Woodward. The research question is: how can innovation in the competitive strategy context of Amazonian fish-farmingare characterized? The Case Study methodis used, with both quantitative and qualitative methodology, and involved consultation with experts and focus groups. As a result, it can be concluded that innovation is the competitive strategy of this venture, characterized by the breakdown of tradition that perpetuates unproductive or high-impact practices. The idealizers of such practices are recommended to internalize them in the policies of the development agencies. This research provides information on the development of public policies for integrated local development and for managers who wish to develop competitive strategies in sustainable fish farming.
\end{abstract}

Palavras-chave: Amazônia. Inovação. Teoria Contingencial. Competitividade. Estratégia.

Keywords: Amazon. Innovation. Contingency theory. Competitiveness. Strategy.

\section{INTRODUÇÃO}

Este trabalho trata sobre a inovação com foco na estratégica competitiva da piscicultura Amazônica. Aborda as tecnologias envolvidas nos processos produtivo sem face ao uso sustentável dos atributos ambientais, visando ao impacto comercial da atividade e a superação das práticas tradicionalmente desenvolvidas.
O Ministério da Pesca e Aquicultura no Brasil, por meio do Plano de Desenvolvimento da Aquicultura Brasileira 2015/2020 (BRASIL, 2015), demonstrou que até o ano de 2013 apenas 38,4\% da produção de pescado tinha origem na aquicultura. Considerando esse fato, e tendo em vista o posicionamento comercial do país em face da demanda mundial crescente por alimentos, o documento traz propostas de políticas

Organizações Rurais \& Agroindustriais, Lavras, v. 20, n. 3/4, p. 234-245, 2018 
públicas voltadas à expansão da produção na aquicultura comercial.

Porem, ao passo em que se projeta a intensificação dessa atividade, Cyrino et al. (2010) já tem apontado para o impacto ambiental decorrente da produção na piscicultura e afirmam que, a existência de manejos ineficientes do ponto de vista ambiental e produtivo, suscita a necessidade de estudos que indiquem direcionadores para a utilização dos conceitos de sustentabilidade nas práticas da piscicultura. Essa reflexão revela-se particularmente importante, considerando que fóruns nacionais e internacionais reconhecem a relevância das questões ambientais no contexto das estratégias de desenvolvimento econômico, especialmente em ecossistemas frágeis como a Amazônia.

O cenário apresentado descreve o problema defrontado neste estudo, o qual busca responder ao questionamento sobre como se caracteriza a inovação com sustentabilidade para a excelência competitiva da atividade de piscicultura na Amazônia. Em face ao exposto, o objetivo geral definido compreende estudar a inovação com foco na estratégica competitiva Amazônica, trazendo como objetivos específicos apontar idealizadores proficientes para a inovação sustentável no cenário em estudo (1); contextualizar a estratégia transformadora em face da conveniência competitiva dos atributos amazônicos (2), e analisar a inovação requerida em face do rompimento da tradição sob o impacto comercial da nova demanda (3).

O Método de Estudo de Caso foi utilizado para direcionar os procedimentos da pesquisa, envolvendo o levantamento da conjuntura estrutural-tecnológica no cenário da piscicultura na municipalidade de Rolim de Moura (Rondônia) - Brasil, para contextualização estratégico-competitiva do cenário de pesquisa. Grupo focal proporcionou a imersão empírica, e o tratamento estatístico destes dados conduziu aos elementos prevalentes, que tratados subsidiariamente com apoio da ferramenta SWOT indicaram a determinação da intervenção proposta.

Este estudo pretende servir para reflexão entre os interessados na elaboração de políticas públicas para o desenvolvimento local integrado e gestores que pretendem formular estratégias competitivas na piscicultura sustentável.

\section{REVISÃO TEÓRICA E CONCEITUAL}

A Teoria Contingencial é trazida como base a tarefa, seguindo a concepção de Joan Woodward conforme indicado em Fagundes (2010), Pereira (2014), Pereira, Rodrigues e Gessi (2014), para orientar a buscar por direcionadores estratégicos à conveniência competitiva da piscicultura. Para esses autores, Woodward evidenciando a relação funcional entre o ambiente e as organizações, ao demonstrar que a tecnologia disponível condiciona o desempenho na organização.

Em face ao exposto, assume-se como pressuposto que a inovação sustentável das práticas produtivas na piscicultura envolve a articulação entre recursos naturais e conhecimento tradicional, como orientação proficiente a determinação da tecnologia e de seu uso enquanto estratégia competitiva nas atividades produtivas.

\subsection{Conceitos sobre Idealizadores Proficientes para a Inovação Sustentável}

Os atributos Amazônicos são indicados por Pedro Filho (2015) como um modo eficiente e eficaz de promover a inovação em empreendimentos sediados na Amazônia, e os conceitua como os recursos de natureza biótica e abiótica proporcionados por aquele bioma, que detém a capacidade de influenciaras práticas tradicionais ali desenvolvidas. Em face à possibilidade de surgimento de efeitos antrópicos indesejáveis nessa relação homem-ecossistema, acompanha-se a perspectiva de sustentabilidade Triple Bottom Line, conforme indicada em Piacentini, Pedro Filho e Almeida (2015) quanto.

Esses entendimentos tomados de modo alinhado à percepção de inovação em processos segundo Andrade (2014), proporciona a perspectiva de que a introdução de melhorias significativas na tecnologia a partir de uma visão Contingencial pode envolvera abordagem sustentável dos atributos da Amazônia, conforme descrito no Quadro 1.

Nesta perspectiva, a inovação sustentável em processos pode ser obtida por meio dos atributos da natureza, tomados de modo sustentável em função da análise sistêmica e contínua das variáveis contingenciais que afetam a estrutura tecnológica e estratégica da organização.

\subsection{Conceitos requeridos para estratégia transformadora e competitividade dos atributos amazônicos}

O foco deste estudo é abordar a inovação em âmbito das tecnologias em processos produtivos tradicionalmente desenvolvidos na piscicultura amazônica, propondo sua transformação de modo estrategicamente orientado ao mercado com o uso sustentável de atributos da Amazônia.

No entendimento de Pereira (2014),a estratégia é o meio pelo qual gestores organizacionais podem influenciar o ambiente externo, as tecnologias da organização, 
estruturas e mecanismos de controle e de gerenciamento. $\mathrm{O}$ autor supracitado apresentar a perspectiva estratégica de Design e a ferramenta SWOT, que envolve dentre outros elementos a avaliação interna da organização como estratégia competitiva.

A competitividade pode ser entendida de modo associado à inovação e a estratégia conforme entendimento de Leão (2014), que entende como a capacidade organizacional de perceber mudanças e de se preparar para enfrentá-las adotando uma postura proativa.

Acrescentando a esses entendimentos a percepção de Cyrino et al. (2010) quanto ao impacto ambiental gerado pela piscicultura, entende-se que nesse cenário a estratégia visa a obtenção de vantagens em termos de custos e competitividade por meio da redução do impacto ambiental decorrente das tecnologias ou métodos de produção tradicionalmente praticados, com base na adoção de direcionadores que reorientem a utilização dos atributos da natureza ali empregados.

\subsection{Conceitos de Inovação, Tradição e Demanda com Foco no Impacto Comercial}

A definição de conhecimento tradicional apresentada em Castelli e Wilkinson (2015) indica que comunidades locais possuem conhecimentos, tecnologias, inovações e práticas que estão inseridas em seus estilos de vida tradicional. Deste modo, o manejo costumeiramente desenvolvido por produtores rurais conforme suas práticas tradicionais representa o resultado de um processo histórico que em última instância lhes definem como coletividade.

Portanto, o aperfeiçoamento das práticas produtivas frente a novas demandas que tenham impacto sobre a tecnologia aplicada na atividade comercial tradicionalmente desenvolvida, representa a revisão de conhecimentos, tecnologias e práticas segundo preceitos teóricos proficientes ao cenário de estudo.

Em Pereira (2014), verifica-se que a tecnologia pode ter um perfil flexível associado ao conhecimento técnico e matérias-primas que podem ser empregadas em diferentes produtos ou serviços. Neste contexto, um produto pode ser descrito como abstrato, se caracterizarse como aquele que detém adaptabilidade com o meio ambiente e flexibilidade tecnológica; estratégia para obter consenso externo e interno; e ênfase nas áreas de pesquisa e desenvolvimento, mercadológico e recursos humanos.

\section{METODOLOGIA}

A inferência neste estudo seguiu estratégia quantitativa para subsidiar analise qualitativa de dados, acompanhando-se as indicações em Coimbra e Martins (2013). Segundo estas autoras, Yin (2011), que preconiza o estudo de caso como um método que propicia a análise aprofundada dos aspectos de um fenômeno, situação ou problema específico; e Punch (2010) reconhecea conjugação de diferentes paradigmas em uma plataforma metodológica comum.

O estudo envolveu consulta a grupo de especialistas composto por professores da Universidade Federal de Rondônia, para debate e definição de parâmetros ideais para sustentabilidade na piscicultura. Utilizou-se a técnica Delphi, conforme indicado em Landeta e Barrutia (2011) e Vanzetto (2012), para estruturação de conhecimento a partir da experiência e criatividade de um painel de especialistas. A matriz metodológica aplicada no

QUADRO 1 - Construto de inovação sustentável em processos no cenário de estudo

\begin{tabular}{|c|c|c|}
\hline Elementos & Conceitos & $\begin{array}{l}\text { Idealizador para inovação } \\
\text { sustentável em processos }\end{array}$ \\
\hline 1Abordagem contingencial & $\begin{array}{l}\text { 1.1 Formato apropriado ao alcance dos objetivos organizacionais } \\
\text { decorrente da relação funcional entre o ambiente e a } \\
\text { organização. }\end{array}$ & \multirow{4}{*}{$\begin{array}{l}\text { Tecnologia ou método novo ou } \\
\text { significativamente melhorado } \\
\text { por meio da apropriação } \\
\text { sustentável dos atributos } \\
\text { Amazônicos em face da análise } \\
\text { de contingências existentes } \\
\text { no ambiente organizacional, } \\
\text { visando impactar na redução } \\
\text { dos custos operacionais e no } \\
\text { aumento de competitividade. }\end{array}$} \\
\hline 2Atributos da natureza & $\begin{array}{l}\text { 2.1 Conjunto de saberes tradicionais que envolvem o uso de } \\
\text { recursos bióticos e/ou abióticos disponíveis no bioma. }\end{array}$ & \\
\hline 3Inovação de processos & $\begin{array}{l}\text { 3.1 Método de produção novo ou significativamente melhorado } \\
\text { visando à redução de custos de produção e competitividade. }\end{array}$ & \\
\hline $\begin{array}{l}\text { 4Abordagemda } \\
\text { Sustentabilidade }\end{array}$ & $\begin{array}{l}\text { 4.1 Interação viável, equitativa e suportável entre as dimensões } \\
\text { ecológica, econômica e ambiental, proporcionando continuidade } \\
\text { no tempo de forma constante ou estável. }\end{array}$ & \\
\hline
\end{tabular}

Fonte: Elaborado pelos autores

Organizações Rurais \& Agroindustriais, Lavras, v. 20, n. 3/4, p. 234-245, 2018 
estudo é representada na Figura 1 e descrita conforme Quadro 2. Nela indica-se a consulta a grupo focal para contextualização estratégico-competitiva do cenário, realizada seguindo o entendimento de Dias (2015). O grupo foi constituído pelos seis piscicultores com maior produtividade na municipalidade de Rolim de Moura, Estado de Rondônia, Brasil e vinte de seus stakeholders.

Utilizou-se subsidiariamente a ferramenta SWOT conforme indicado em Chiavenato (2014),para tratar aspectos inerentes ao contexto da estratégia competitiva no cenário da piscicultura. Na Figura 2 está o delineamento ora tratado, seguido das descritivas constantes dos Quadros 3 e 4.

Os instrumentos auxiliares aplicados foram a Escala de Likert com suporte do software Statistical Package for Social Science for Windows (SPSS), para tratamento da correlação segundo o Coeficiente de Pearson.

De acordo com Vale, Teixeira e Sant'Anna (2015), a análise de correlação simples por meio do Coeficiente de Pearson, poderá indicar informações sobre o tipo

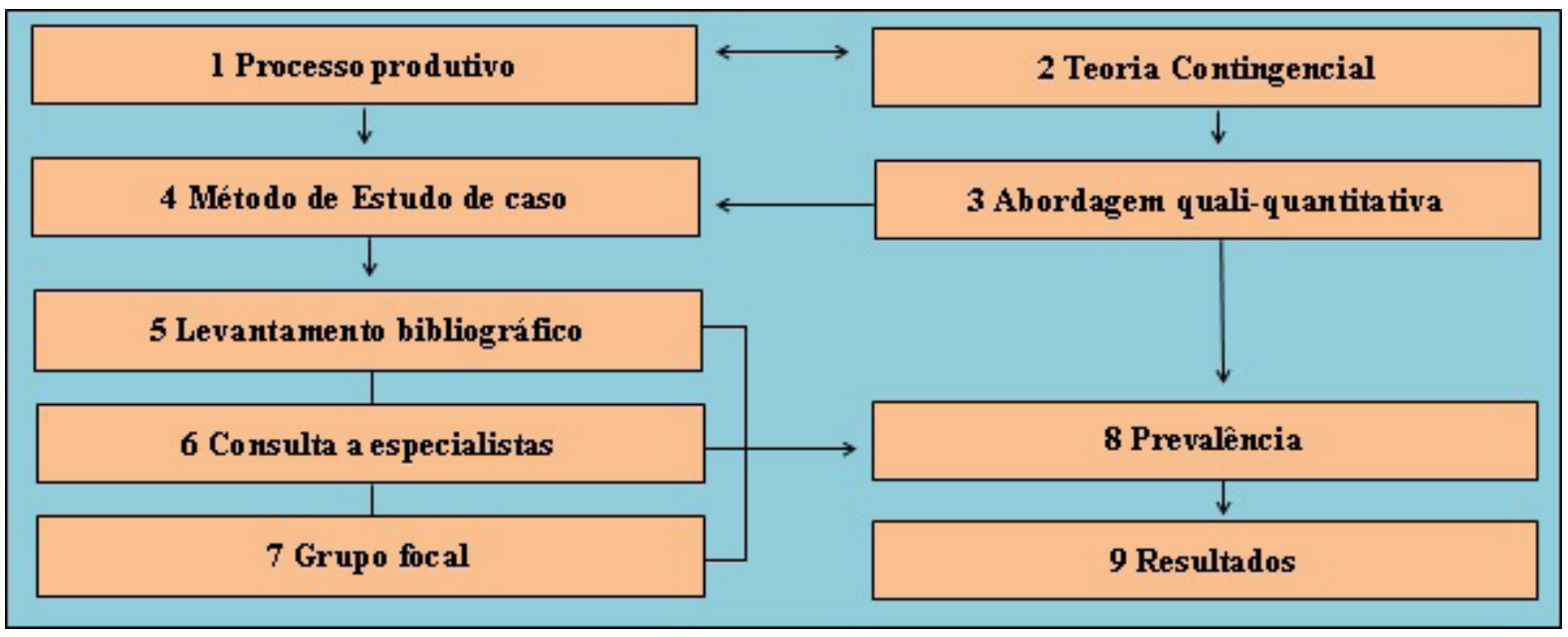

FIGURA 1 - Matriz metodológica da pesquisa

Fonte: Elaborado pelos autores

QUADRO 2 - Descritiva da matriz metodológica da pesquisa

\begin{tabular}{|l|c|}
\hline \multicolumn{1}{|c|}{ Elemento } & Descrição \\
\hline 1 Processo produtivo & Objeto de estudo da pesquisa: inovação em processos produtivos na piscicultura. \\
\hline 2 Teoria Contingencial & $\begin{array}{c}\text { Teoria de base para a tarefa, seguindo a abordagem tecnológica decorrente dos estudos } \\
\text { realizados por Joan Woodward. }\end{array}$ \\
\hline 3 Abordagem quali-quantitativa & Paradigma de abordagem que norteia a natureza do estudo. \\
\hline 4 Método de Estudo de caso & Abordagem metodológica para realização da pesquisa. \\
\hline 5 Levantamento bibliográfico & Categorização teórica em suporte ao estudo. \\
\hline 6 Consulta a especialistas & $\begin{array}{c}\text { Levantamento de parâmetros e variáveis desejáveis às categorias envolvendo atributos } \\
\text { Amazônicos tomados de modo sustentável. }\end{array}$ \\
\hline 7Grupo focal & $\begin{array}{c}\text { Identificação do contexto fático segundo piscicultores e stake holders, tendo como base as } \\
\text { categorias elencadas na teoria. }\end{array}$ \\
\hline 8Prevalência & $\begin{array}{c}\text { Medidas relevantes que se destacam no cenário de estudo, identificadas com base aferição } \\
\text { estatística dos dados coletados. }\end{array}$ \\
\hline 9Resultados & $\begin{array}{c}\text { Elucidação das prevalências visando à compatibilização entre a estratégia eo ajustamento } \\
\text { estrutural da organização. }\end{array}$ \\
\hline
\end{tabular}

Fonte: Elaborado pelos autores

Organizações Rurais \& Agroindustriais, Lavras, v. 20, n. 3/4, p. 234-245, 2018 
de associação entre as variáveis estudadas. Conforme Almeida (2014), se o resultado da correlação for positiva, indicará uma relação direta de correspondência entre as variáveis; se a correlação apresentar valor negativo, indicará que há uma relação de natureza inversa entre as variáveis; se o valor de correlação for igual ou próximo zero indicará que não há correlação entre as variáveis.
A providência indicada na Figura 3 e descrita no Quadro 5, permitiu a aferiçãodas proximidades entre os conjuntos de dados, a identificação das variáveis e da matriz ideal em face dos elementos conceituais considerados, bem como, a análise crítica.

A consulta a especialistas forneceu descritivas do estado ideal para as variáveis no cenário Amazônico,

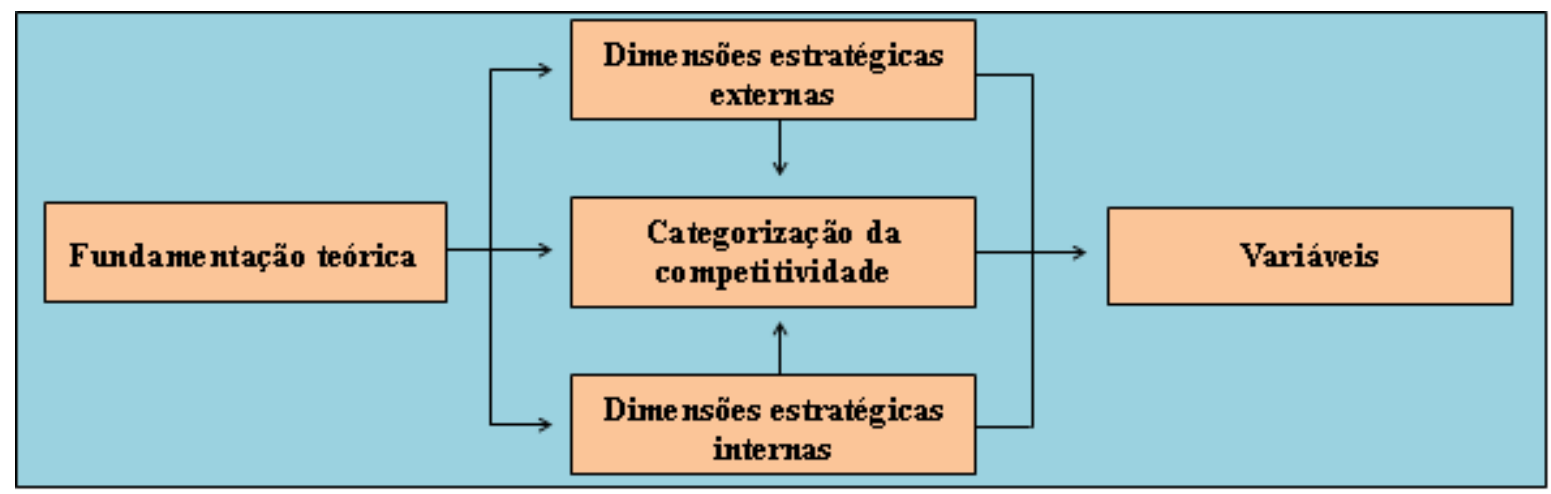

FIGURA 2 - Matriz teórica da pesquisa

Fonte: Elaborado pelos autores

QUADRO 3 - Descritiva da matriz teórica da pesquisa

\begin{tabular}{|c|c|}
\hline Orientação teórica & Detalhamento da matriz teórica \\
\hline Fundamentação teórica & $\begin{array}{c}\text { A Teoria Contingencial envolve estruturas de arranjos altamente específicos e dinâmicos, } \\
\text { sujeitos a ajustes e variações em razão da dinâmica ambiental, relacionada a fatores externos } \\
\text { e internos que afetam o desempenho da organização. }\end{array}$ \\
\hline $\begin{array}{c}\text { Categorização da } \\
\text { competitividade }\end{array}$ & $\begin{array}{r}\text { Produto ou processo novo ou melhorado com o uso sustentável de atributos naturais da } \\
\text { Amazônia tomados a partir da percepção de mudanças contingenciais. }\end{array}$ \\
\hline
\end{tabular}

Fonte: Mantovani (2012) e Pereira (2014),Andrade (2014), Pedro Filho (2014), Pereira (2014)

QUADRO 4 - Dados coletados com base na consulta a especialistas e estruturado conforme ferramenta SWOT

\begin{tabular}{|c|c|c|}
\hline \multicolumn{2}{|c|}{ Dimensões estratégicas e indicadores } & Variáveis \\
\hline \multirow{2}{*}{ Externas } & 1Oportunidades (opportunities). & $\begin{array}{l}\text { 1.1 Novas linhas de produtos; } \\
\text { 1.2 Novas tecnologias; } \\
1.3 \text { Novos processos; }\end{array}$ \\
\hline & 2Ameaças (threats). & $\begin{array}{l}\text { 2.1 Produtos substitutivos; } \\
\text { 2.2 Novas demandas dos clientes; } \\
\text { 2.3 Pressões competitivas; }\end{array}$ \\
\hline \multirow{2}{*}{ Internas } & 3Forças (strengths). & $\begin{array}{l}\text { 3.1 Recursos naturais disponíveis; } \\
\text { 3.2 Tecnologias avançadas; } \\
\text { 3.3 Processos eficientes; }\end{array}$ \\
\hline & 4Fraquezas (weakness). & $\begin{array}{l}\text { 4.1 Limitações operacionais; } \\
\text { 4.2 Tecnologias obsoletas; } \\
\text { 4.3 Processos ineficientes; }\end{array}$ \\
\hline
\end{tabular}

Fonte: Elaborado pelos autores

Organizações Rurais \& Agroindustriais, Lavras, v. 20, n. 3/4, p. 234-245, 2018 
estabelecendo estes atributos da natureza comparâmetros de intervenção pró-inovação. O grupo focal ofereceu a identificação do contexto fático conforme tradicionalmente praticado e percebido pelos respondentes. Ranking médio foi utilizado para tratamento das medidas obtidas via escala de Likert, seguida de análise de correlação por meio do Coeficiente de Correlação de Pearson, para apurar a força de associação entre as variáveis e inferira prevalência de elementos significativos que podem ser inovados para romper com a tradição em busca da excelência competitiva.

\section{INOVAÇÃO PELA ABORDAGEM DE JOAN WOODWARD FOCALIZANDO A PISCICULTURA NA AMAZÔNIA}

A análise da produção de pescado brasileira, apresentada no Plano de Desenvolvimento da Aquicultura Brasileira 2015/2020 (BRASIL, 2015), evidenciou que no ano de 2013 obteve-se uma produção de 1.241.807 toneladas, sendo que, deste total $61,6 \%$ foram provenientes da pesca e apenas $38,4 \%$ tiveram origem na aquicultura.
Os dados oficiais publicados pelo Instituto Brasileiro de Geografia e Estatística (IBGE, 2015), indicam que a Região Norte do País responde por apenas 15,32\% da produção de peixe em cativeiro, na qual prevalecem os espécimes Tambaqui, Pirarucu e Pirapitinga (Colossoma macropomum, Arapaima gigas e Piaractus brachypomus).

O fato de a Bacia Amazônia, considerada a maior bacia hidrográfica do mundo,situar-se nessa Região pode ajudar a explicar o fato de prevalecer a comercialização proveniente da pesca ao invés da produção em cativeiro. No entanto, a pressão antrópica exercida sobre essa bacia hídrica não apenas pela extração de pescado mas também por outras atividades como navegação, inclusive com embarcações pesadas, pode provocar a exaustão dos recursos pesqueiros, acarretando fragilidade econômica, ambiental e social na Região.

É nesse cenário que se discute a situação do Município de Rolim de Moura,cuja localização é indicada na Figura 4. A produção pesqueira nessa Municipalidade é predominante em cativeiro, tendo comercializado

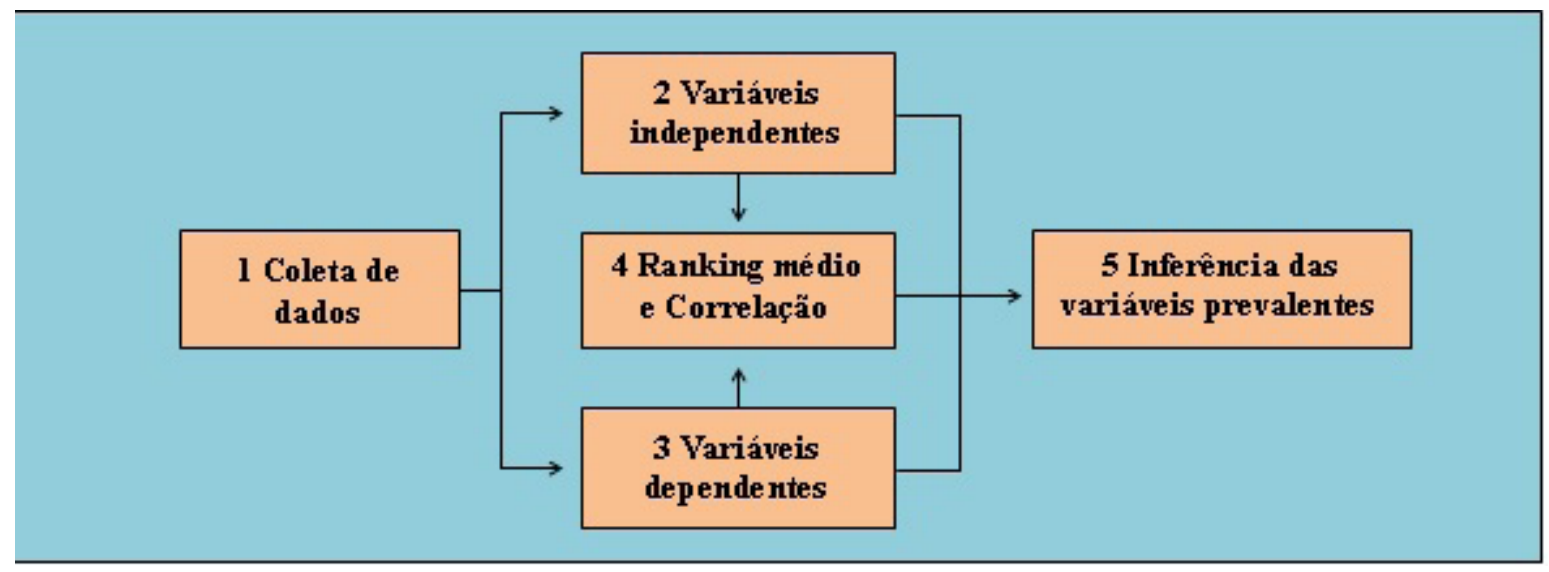

FIGURA 3 - Matriz para teste de aferição

Fonte: Próprios autores

QUADRO 5 - Descritiva da matriz para teste de aferição

\begin{tabular}{|c|c|}
\hline Elementos & Descritivas \\
\hline 1Coleta de dados. & 1.1 Aplicação de questionário em base Likert para levantamento de dados. \\
\hline 2Variáveis independentes. & 2.1 Parâmetros para a mensuração, obtido por meio da consulta à piscicultores. \\
\hline 3Variáveis dependentes. & 3.1 Parâmetros aferidos com base em pesquisa junto à stakeholders dos produtores. \\
\hline 4Ranking médio e correlação. & 4.1 Tratamento estatístico para análise de dados com base na aferição dos parâmetros, em \\
Coeficiente de Correlação de Pearson.
\end{tabular}

Fonte: Próprios autores

Organizações Rurais \& Agroindustriais, Lavras, v. 20, n. 3/4, p. 234-245, 2018 
aproximadamente 1,5 ton. para abastecer principalmente feiras e supermercados locais e nas cidades circunvizinhas. Tendo em vista que em seu Plano de Desenvolvimento da Aquicultura (BRASIL, 2015) o País delineia expandir sua produção de pescado por meio da aquicultura comercial, e considerando a necessidade de aumento na produção de alimento para atender a população mundial, assim como, a demanda crescente por alimentos mais saudáveis, entende-se que é oportuno propor a ampliação da produção de pescado em confinamento no Município de Rolim de Moura, não apenas pela abundância de meios aquíferos ora subutilizados como também pela notória qualidade comercial e nutricional das espécies ali consolidadas.

Porém, em que se pese a presença de órgãos estatais para fomento e tecnificação da produção rural, a aquicultura na localidade utiliza meios predominantemente tradicionais, pouco eficientes no planejamento, desenvolvimento e controle da atividade de produção, comercialização e controle dos impactos ambientais decorrentes.
Deste modo, nos tópicos seguintes elencam-se idealizadores para a inovação sustentável no contexto de estudo, contextualiza-se a estratégia transformadora em face da conveniência competitiva dos atributos amazônicos, e analisa-se a inovação requerida em face do rompimento da tradição sobre o impacto comercial da nova demanda.

\subsection{Idealizadores Proficientes à Inovação Sustentável no Cenário de Estudo}

Indicativos provenientes de consulta a especialistas foram tomados como parâmetros representativos do contexto, conforme direcionadores elencado no Quadro 6. Baseia-se na apropriação sustentável de atributos Amazônicos, tomados a partir da análise sistêmica de contingências, e visa à orientação da intervenção pró-inovação tecnológica com impacto no redução de custos operacionais e ganho de competitividade.

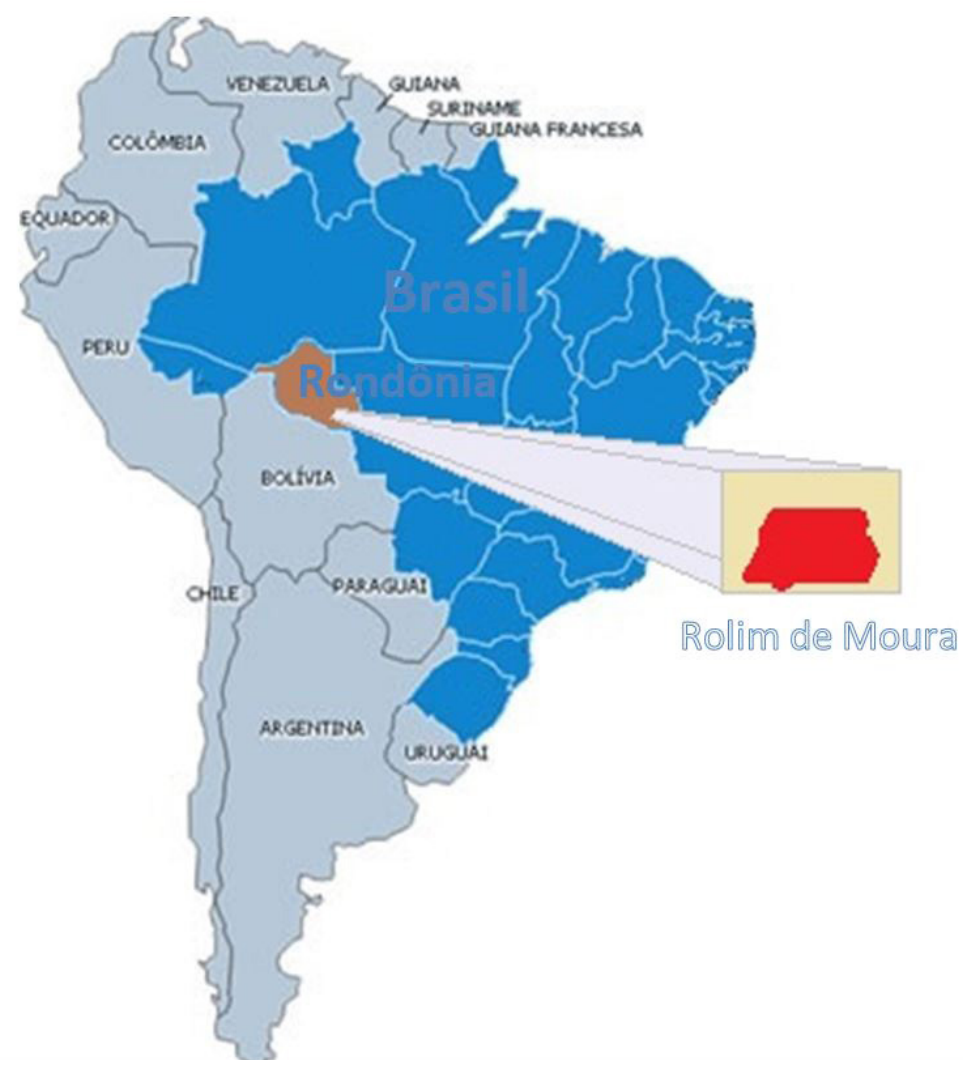

FIGURA 4 - Localização do Município de Rolim de Moura Fonte: Elaborado pelos autores

Organizações Rurais \& Agroindustriais, Lavras, v. 20, n. 3/4, p. 234-245, 2018 
QUADRO 6 - Parâmetros de referência para intervenção pró-inovação

\begin{tabular}{|c|c|c|c|}
\hline \multicolumn{2}{|c|}{$\begin{array}{c}\text { Dimensões estratégicas e } \\
\text { indicadores }\end{array}$} & Variáveis & Direcionadorespara intervenção pró-inovação com sustentabilidade \\
\hline \multirow{2}{*}{ 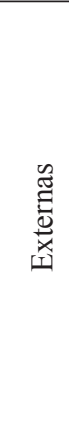 } & $\begin{array}{l}1 \text { Oportunidades } \\
\text { (opportunities). }\end{array}$ & $\begin{array}{l}\text { Novas linhas de produtos; } \\
\text { Novas tecnologias; } \\
1.3 \text { Novos processos; }\end{array}$ & $\begin{array}{l}\text { 1.1.1 Filetamento: Corte diferenciado do peixe como alternativa a } \\
\text { tradicional em peças inteiras. } \\
\text { 1.2.1 Atributos amazônicos: processamento de resíduos e criação } \\
\text { em tanques redes. } \\
\text { 1.3.1 Controle sanitário: Sanitização da produção transformando } \\
\text { subprodutos em ração. }\end{array}$ \\
\hline & $\begin{array}{l}2 \text { Ameaças } \\
\text { (threats). }\end{array}$ & $\begin{array}{l}\text { 2.1 Produtos substitutivos; } \\
\text { 2.2 Demandas dos clientes; } \\
\text { 2.3 Pressões de entrantes; }\end{array}$ & $\begin{array}{l}\text { 2.1.1 Competitividade: Preços vantajosos em face ao ofertado. } \\
\text { 2.2.1 Preferência do consumidor: Declínio da demanda face à } \\
\text { exigência dos consumidores. } \\
\text { 2.3.1 Enfraquecimento pela concorrência: Deficiências impactando } \\
\text { negativamente o negócio. }\end{array}$ \\
\hline \multirow{2}{*}{ 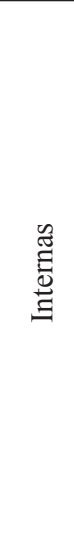 } & $\begin{array}{l}3 \text { Forças } \\
\text { (strengths). }\end{array}$ & $\begin{array}{c}\text { 3.1 Recursos naturais } \\
\text { disponíveis; } \\
\text { 3.2 Tecnologias avançadas; }\end{array}$ & $\begin{array}{l}\text { 3.1.1 Disponibilidade de espécimes: Dispensa importação, } \\
\text { adaptação de espécies exógenas. } \\
\text { 3.2.1 Técnica de alevinagem, policultivo e consórcio: reprodução e } \\
\text { criação em com outros animais. } \\
\text { 3.3.1 Criação semi-intensivae cooperativa: Ênfase no controle } \\
\text { intensivo da produção e cooperação ou colaboração entre } \\
\text { produtores. }\end{array}$ \\
\hline & $\begin{array}{l}4 \text { Fraquezas } \\
\text { (weakness). }\end{array}$ & $\begin{array}{l}\text { 4.2 Tecnologias obsoletas; } \\
\text { 4.3 Processos ineficientes; }\end{array}$ & $\begin{array}{l}\text { 4.1.1 Organização e qualificação: Desqualificação dos stakeholders } \\
\text { reproduzindo práticas tradicionais ineficientes impactantes. } \\
\text { 4.2.1 Criação de modo extensivo: Sistema tradicional baixa } \\
\text { tecnificação e produtividade. } \\
\text { 4.3.1 Falta de planejamento pecuário e controle zootécnico: } \\
\text { Ausência de planejamento da estrutura de criação, rentabilidade e } \\
\text { medidas biométricas comprometem a atividade. }\end{array}$ \\
\hline
\end{tabular}

Fonte: Elaborado pelos autores

No que se refere ao indicador Oportunidades, a indicação de filetamento se constitui uma alternativa ao modus operandi tradicional; por outro lado existe uma realidade fática que é a falta de tecnologia ou de capacitação para a inovação no próprio processo de transformação do produto segundo exigência do mercado moderno.Essa falta de tecnologia também se relaciona, de alguma forma, ao despreparo da agência de assistência técnica e mesmo a falta de consolidação de políticas públicas voltadas para o fortalecimento do setor.

A utilização dos atributos amazônicos, poderá ocorrer com a otimização no aproveitamento dos recursos naturais como o rio ou o reservatório de represas hidrelétricas; aqui serão gerados insumos como adubos orgânicos e outros, provenientes do criadouro com controle ambiental da atividade. A sanitização propiciará a redução de custos mediante a transformação dos resíduos da produção em ração reaproveitável no processo produtivo.

Quanto às ameaças, se a elevação dos custos de produção não significar ganho de qualidade competitiva, pode impactar a demanda elevando o preço praticado na comercialização e provocando a busca por produtos alternativos mais vantajosos. Neste caso, a demanda por qualidade do consumidor também pode resultar em declínio da demanda, frente produtos de outras regiões ou produtos substitutivos aos ofertados.

Processos produtivos deficitários podem fragilizar posições de mercado conquistadas anteriormente, em face à pressão de novos concorrentes. Dentre os fatores que proporcionam o fortalecimento da piscicultura encontramse a disponibilidade de recursos hídricos e a diversidade de espécies provenientes do próprio habitat amazônico. Em conjunto estes são fatores de produção que favorecem o sucesso na atividade estimulando a criação e reprodução de matrizes bem como, a demanda e aceitação do produto no mercado local.

A tecnologia de produção de alevinos amplia qualitativamente e quantitativamente a possibilidade de criação, que pode ser expandida pela criação conjunta de peixes de espécies diferentes ou em interação com outros 
animais que proporcionem insumos úteis à produção, aumentando a eficiência produtiva e competitiva do processo.

A criação semi-intensiva revela-se adequada a busca de produtividade com qualidade, por ter ênfase no controle de recursos bióticos e abióticos que interagem com a produção, assim como por adensar o quantitativo de peixes e intensificar a alimentação visando acelerar o processo produtivo.

Relativamente às fraquezas identificadas no setor, limitações do produtor na organização da atividade produtiva e a falta demão de obra qualificada, contribuem para que práticas consideradas pouco produtivas ou altamente impactantes ao meio ambiente permaneçam em uso. Neste contexto, quando a abordagem da atividade e considerada como algo secundário no contexto produtivo da propriedade, ocasiona um trato amadorístico na condução do negócio, acentuando a opção por tecnologias obsoletas tal qual a criação de modo extensivo, com baixa produtividade em relação ao modo semi-intensivo. A adoção de processos menos complexos no planejamento da atividade, descartara escolha das espécies, a definição de publico alvo, o controle zootécnico da produção, monitoramento da qualidade da água, controle biométrico, pesagem e medição dos peixes.

\subsection{Contextualização da Estratégia Transformadora em face da Conveniência Competitiva dos Atributos Amazônicos}

Os resultados da pesquisa efetuada para avaliar conveniência competitiva da atividade, foram submetidos a tratamento estatístico para sistematização das respostas, utilizando-se o Ranking Médio Geral como fator representativo das respostas de cada grupo segundo a escala Likert, conforme apresentado nos Quadros 7 e 8.

Os resultados propiciam a análise segundo as dimensões estratégicas que impactam a competivida de no cenário de estudo. Na dimensão estratégica Externa, as variáveis ligadas à categoria Oportunidades não foram indicadas como elementos que afete mo desempenho organizacional, o que poderia representar limitações na

QUADRO 7 - Parâmetros de avaliação

\begin{tabular}{|c|c|}
\hline Avaliação & Condicionantes \\
\hline Abaixo de 3 & Afeta negativamente a atividade. \\
\hline Entre 3 e 4 & Indiferente a atividade. \\
\hline Acima de 4 & Afeta positivamente a atividade. \\
\hline
\end{tabular}

Fonte: Elaborado pelos autores

QUADRO 8 - Resultados obtidos

\begin{tabular}{|c|c|c|c|c|c|}
\hline \multicolumn{2}{|c|}{ Dimensões estratégicas } & Variáveis Ranking médio & $\begin{array}{c}\text { Piscicultores } \\
\text { Ranking médio }\end{array}$ & $\begin{array}{c}\text { Stakeholders } \\
\text { Ranking médio }\end{array}$ & Gera \\
\hline \multirow{6}{*}{ 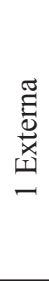 } & \multirow{3}{*}{ 1.1 Oportunidades } & 1.1.1 Novas linhas de produtos. & 3,50 & 3,75 & 3,63 \\
\hline & & 1.1.2 Novas tecnologias. & 4,00 & 3,25 & 3,63 \\
\hline & & 1.1.3 Novos processos. & 3,50 & 3,30 & 3,40 \\
\hline & \multirow{3}{*}{ 1.2 Ameaças } & 1.2.1 Produtos substitutivos. & 1,33 & 2,10 & 1,72 \\
\hline & & 1.2.2 Novas demandas dos clientes. & 1,33 & 1,80 & 1,57 \\
\hline & & 1.2.3 Pressões competitivas. & 1,00 & 2,75 & 1,88 \\
\hline \multirow{6}{*}{ 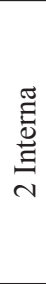 } & \multirow{3}{*}{ 2.1 Forças } & 2.1.1 Recursos naturais disponíveis. & 5,00 & 4,60 & 4,80 \\
\hline & & 2.1.2 Tecnologias avançadas. & 2,67 & 2,60 & 2,63 \\
\hline & & 2.1.3 Processos eficientes. & 4,00 & 3,40 & 3,70 \\
\hline & \multirow{3}{*}{ 2.2 Fraquezas } & 2.2.1 Limitações operacionais. & 2,00 & 3,00 & 2,50 \\
\hline & & 2.2.2 Tecnologias obsoletas. & 2,17 & 3,25 & 2,71 \\
\hline & & 2.2.3 Processos ineficientes. & 2,17 & 3,00 & 2,58 \\
\hline
\end{tabular}

Fonte: Elaborado pelos autores.

Organizações Rurais \& Agroindustriais, Lavras, v. 20, n. 3/4, p. 234-245, 2018 
percepção dos respondentes quanto ao ambiente do setor, se a categoria Ameaças não tivesse recebido destaque tão expressivo, indicando que as variáveis de mercado exercem grande influência sobre o setor.

Na dimensão estratégica Interna, a categoria Forças destaca a variável Recursos Naturais como o fator que mais afeta positivamente seus resultados da atividade. $\mathrm{O}$ resultado da variável Tecnologias Avançadas indica que estes recursos tem afetado negativamente o desempenho do setor, coadunando com o representado na Categoria Fraquezas, pela variável Tecnologias Obsoletas, como responsável por fragilidades no desempenho competitivo. As variáveis Limitações Operacionais e Processos Ineficientes também são considerados críticas, embora esses elementos tenham sido assim considerados apenas à ótica dos piscicultores.

\subsection{Análise Sobre a Inovação Requerida para o Rompimento da Tradição em face ao Impacto Comercial da Nova Demanda}

O software SPSS gerou o Coeficiente de Correlação de Pearson para as variáveis contidas no Quadro 7, indicado no subtópico anterior, cuja aferição foi transformada em indicativos de semelhança e diferença ou distância aproximadas entre os vetores de valores. Estes passos permitiram revelar os elementos prevalentes,caracterizados pela maior força de associação, e a construção da matriz aqui retratada, representando a perspectiva de ajustamento entre a conjuntura estrutural-tecnológica do cenário tradicional.
Os resultados dessa análise podem conduzir ao rompimento da tradição para a busca da excelência inovadora, conforme direcionadores indicados no Quadro 9. Os elementos prevalentes comprovados pela correlação das variáveis encontra o ponto ótimo na articulação das dimensões, caracterizando o arranjo ideal para efeito de intervenção.

Nesta perspectiva, o filetamento do peixe é uma oportunidade de inovar o produto oferecido, desde que inclua a percepção de qualidade requerida pelos clientes. Esta nova linha de produtos pode ser ampliada mediante a diversificação dos espécimes do habitat amazônico, fazendo-se uso da representativa força competitiva proporcionada pelos recursos disponíveis.

A perspectiva de diversificação nas espécies supera o monocultivo tradicional, com base no consórcio com outras espécies de peixes ou de animais, potencializando o processo produtivo pela implementação do sistema de criação semi-intensiva; ao tempo em que atende à demanda de qualidade exigida pelos clientes, anula esse parâmetro como ameaça, eliminando a fraqueza proveniente de processos ineficientes.Não obstante a isso, o aumento qualitativo e quantitativo da produção também pode ocorrer por meio do compartilhamento ou colaboração entre produtores envolvidos em sistema cooperativo, embora seja imprescindível implementar o planejamento pecuário e controle zootécnico.

Considera-se que o rompimento da tradição em sua acepção negativa, que perpetua práticas improdutivas ou de alto impacto, ocorreu no eixo da interação entre os

QUADRO 9 - Prevalências estatísticas dos dados como direcionadores críveis de intervenção.

\begin{tabular}{|c|c|c|c|}
\hline \multicolumn{2}{|c|}{ Dimensões estratégicas } & Variáveis & Direcionadores de prevalênciapró-inovação com sustentabilidade \\
\hline \multirow{2}{*}{ 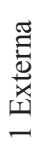 } & $\begin{array}{l}\text { 1.1 Oportunidades } \\
\text { (opportunities). }\end{array}$ & $\begin{array}{l}\text { 1.1.1 Novas linhas de } \\
\text { produtos; }\end{array}$ & $\begin{array}{l}\text { Filetamento: É o corte do peixe em formato diferenciado, como uma } \\
\text { alternativa ao tradicionalmente comercializado que é em peças inteiras. }\end{array}$ \\
\hline & $\begin{array}{l}\text { 1.2 Ameaças } \\
\text { (threats). }\end{array}$ & $\begin{array}{l}\text { 1.2.1 Novas demandas } \\
\text { dos clientes; }\end{array}$ & $\begin{array}{l}\text { Preferência do consumidor: Pode resultar no declínio da demanda em da } \\
\text { exigência dos consumidores por qualidade. }\end{array}$ \\
\hline \multirow{3}{*}{ 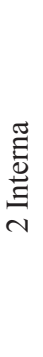 } & \multirow{2}{*}{$\begin{array}{l}2.1 \text { Forças } \\
\text { (strengths). }\end{array}$} & $\begin{array}{l}\text { 2.1.1 Recursos } \\
\text { disponíveis; }\end{array}$ & $\begin{array}{l}\text { Disponibilidade de matrizes de espécimes pesqueiras, e abundância dos } \\
\text { meios aquíferos: Não será necessária a importação ou adaptação de matrizes, } \\
\text { associada à abundância hídrica na Amazônia. }\end{array}$ \\
\hline & & $\begin{array}{l}\text { 2.2.1 Processos } \\
\text { eficientes; }\end{array}$ & $\begin{array}{l}\text { Criação semi-intensiva e arranjo operacional em sistema cooperativo: Ênfase na } \\
\text { produtividade por meio do controle intensivo da produção e o compartilhamento } \\
\text { ou colaboração entre produtores envolvidos em sistema cooperativo. }\end{array}$ \\
\hline & $\begin{array}{l}\text { 2.2 Fraquezas } \\
\text { (weakness). }\end{array}$ & $\begin{array}{l}\text { 2.2.2 Processos } \\
\text { ineficientes; }\end{array}$ & $\begin{array}{l}\text { Falta de planejamento pecuário e controle zootécnico: Ausência de planejamento } \\
\text { da produção e rentabilidade do negócio;a falta de medidas biométricas e demais } \\
\text { controles ligados ao ciclo de produção comprometem o sucesso da atividade. }\end{array}$ \\
\hline
\end{tabular}

Fonte: Elaborado pelos autores 
parâmetros de novas linhas de produtos, novas demandas de clientes, recursos disponíveis, e na relação entre a eficiência e ineficiência dos processos. Portanto, o impacto da nova demanda ocorrerá na perspectiva de oferecer novos produtos alinhados aos interesses dos clientes sem, contudo, descaracterizar conhecimentos e práticas produtivas reconhecidamente efetivas.

A proposta de articulação entre os produtores, de modo a aumentar a produção e promover o compartilhamento de boas práticas para não comprometer a qualidade, pode favorecer o surgimento de uma economia mais sólida e articulada, rompendo com modos de produção tradicionalmente praticados.

\section{CONCLUSÕES}

Esta pesquisa estudou a inovação com foco na estratégica competitiva Amazônica, propondo a apropriação sustentável dos atributos naturais presentes neste bioma na construção de tecnologias e métodos que proporcionem redução de custo e ganho de competitividade aos piscicultores. Para tanto, se providenciou consulta a especialistas para levantamento da conjuntura estruturaltecnológica no cenário da piscicultura; grupo focal foi ouvido para contextualização estratégico-competitiva do mesmo contexto de pesquisa; o tratamento estatístico destes dados conduziu aos elementos prevalentes, que tratados subsidiariamente com apoio da ferramenta SWOT.

Empregando esses idealizadores na pesquisa, foi possível propor parâmetros aplicados ao contexto fático e produzir subsídios que, tomados cognitivamente, revelaram vias para novos métodos e processos, ou melhorias significativas nos já existentes.

No que diz respeito ao objetivo de contextualizar a estratégia transformadora,para romper com a tradição na atividade da piscicultura, o filetamento do peixe é uma oportunidade de inovar o produto oferecido, desde que inclua a percepção de qualidade requerida pelos clientes. Esta nova linha de produtos pode ser ampliada mediante a diversificação dos espécimes do habitat amazônico, fazendo-se uso da representativa força competitiva proporcionada pelos recursos disponíveis.

Para fazer face aos processos ineficientes, a opção pela implementação do sistema de criação semi-intensiva pode atender à demanda de qualidade exigida pelos clientes ao tempo em que a anula como ameaça.Não obstante a isso, o aumento qualitativo e quantitativo da produção também pode ser ocorrer por meio do compartilhamento ou colaboração entre produtores envolvidos em sistema cooperativo, em conjunto com a implementação de planejamento pecuário e controle zootécnico.

Quanto ao objetivo de analisar a inovação requerida em face do rompimento da tradição apontou como a excelência inovadora ocorrerá na forma de uma estratégia competitiva, revelando indicativos que podem reconectar a produção à demanda de mercado, rompendo o trato amadorístico que acentua a opção por tecnologias obsoletas.

Por fim, tendo em vista responder ao questionamento que norteou esse estudo, a inovação no contexto da excelência competitiva da piscicultura Amazônica,se caracteriza pelo rompimento da tradição que perpetua práticas improdutivas ou de alto impacto; no caso em questão, no eixo da interação entre os parâmetros de novas linhas de produtos, novas demandas de clientes, recursos disponíveis, e na relação entre a eficiência e ineficiência dos processos.

A excelência na inovação está em realinhar a produção ao mercado sem desprezar os fatores e elementos históricos e favoráveis à atividade produtiva, valorizando e empregando contingencialmente recursos da natureza, proporcionando a sustentabilidade ambiental, econômica e social no cenário de estudo.Diante desses resultados é possível afirmar que, com base nos idealizadores proficientes para a inovação sustentável empregados no cenário de estudo, é possível reconectar a produção com a demanda de mercado sem ignorar os fatores e elementos históricos e favoráveis à atividade produtiva.

No entanto, embora os idealizadores propostos tenham se revelado compatíveis com o contexto fático no cenário de estudo, proporcionando aos produtores indicativos operacionais válidos, entende-se que a superação do trato amadorístico que acentua a opção por tecnologias obsoletas na condução do negócio demanda também que esses idealizadores sejam internalizados nas políticas dos órgãos estatais de fomento que atuam em favor da piscicultura. Esse estudo pretende servirà reflexão entre os interessados na elaboração de políticas públicas para o desenvolvimento integrado da Amazônia e para piscicultores.

\section{AGRADECIMENTOS}

Agradecemos à Universidade da Beira Interior, Faculdade de Ciências Sociais e Humanas, Departamento de Gestão e Economia, Programa de Pós-Doutoramento em Gestão e Economia, com foco em Estratégia de Gestão para Inovação e Sustentabilidade, Covilhã, Portugal. Site: http:// www.ubi.pt/Entidade/Ciencias_Sociais_e_Humanas. 


\section{REFERÊNCIAS}

ALMEIDA, L. F. (2014). O uso de tecnologias da informação e comunicação em áreas rurais é suficiente para a educação continuada?. Jornal Brasileiro de Tele Saúde, 3(1). Recuperado de http://www.e-publicacoes. uerj.br/index.php/jbtelessaude/article/view/10232/8017.

ANDRADE, A. F. (2014). Investigação da percepção dos envolvidos em inovação no processo produtivo: survey aplicado em indústrias químicas de Curitiba e região metropolitana (Dissertação de Mestrado). Universidade Federal do Paraná, Curitiba, Paraná, Brasil.

BRASIL. (2015). Plano de Desenvolvimento da Aquicultura Brasileira - 2015/2020. Recuperado de http://www.mpa.gov.br/files/docs/Outros/2015/Plano_de_ Desenvolvimento_da_Aquicultura-2015-2020.pdf.

CASTELLI, P. G.; WILKINSON, J. Conhecimento tradicional, inovação e direitos de proteção. Estudos Sociedade e Agricultura, 19, 89-112. Recuperado de http://r1.ufrrj.br/esa/V2/ojs/index.php/esa/article/ viewFile/221/217.

COIMBRA, M. N. C. T.; MARTINS, A. M. O. (2013). O estudo de caso como abordagem metodológica no ensino superior. Nuances: estudos sobre Educação, 24(3), 31-46.

CYRINO, J. E. P. et al. (2010). A piscicultura e o ambiente - o uso de alimentos ambientalmente corretos em piscicultura. Revista Brasileira de Zootecnia, 39, 68-87.

DIAS, C. A. (2015). Grupo Focal: técnica de coleta de dados em pesquisas qualitativas. I\&S, 10(2), Recuperado de http://periodicos.ufpb.br/ojs/index.php/ies/article/ view/330/252.

FAGUNDES, J. A. (2010). Gestão do Curso de Administração Considerando o Enfoque da Teoria da Contingência. Revista de Contabilidade do Mestrado em Ciências Contábeis da UERJ, 14(3), 44-59.

IBGE - Instituto Brasileiro de Geografia e Estatística. (2013). Cidades: Rolim de Moura/Rondônia. Recuperado de http://www.cidades.ibge.gov.br/xtras/temas.php?lang= $\&$ codmun $=110028 \&$ idtema $=135 \&$ search $=$ rondonia $\% 7 \mathrm{Cr}$ olim-de-moura\%7Cpecuaria-2013.
LANDETA, J.; BARRUTIA, J. (2011).People consultation to construct the future: a delphi application. International Journal of forecasting, 27(1), 134-151.

LEÃO, J. A. A. (2014). Inovação Científica para o Desenvolvimento Institucional:Estudo de Caso Instituto Federal de Educação, Ciência e Tecnologia do Acre - IFAC (Dissertação de Mestrado). Universidade Federal de Rondônia, Porto Velho, Rondônia, Brasil.

PEDRO FILHO, F. (2015). Inovação e Sustentabilidade. Porto Velho: PPGMAD/UNIR.

PEREIRA, D. S.; RODRIGUES, M. R.; GESSI, N. L. (2014). Teoria contingencial: uma abordagem teórica sobre sua evolução. Recuperado de http:// redcidir.org/multimedia/pdf/trabajos seleccionados/ Seleccionados-V-Simposio/Asociativismo-empresas-einnovaci\%C3\%B3n/78-TEORIA-CONTINGENCIAL. pdf.

PEREIRA,W. P. (2014). Perfil de incubadora tecnológica em face aos arranjos produtivos locais na municipalidade de Porto Velho, capital do Estado de Rondônia, Brasil (Dissertação de Mestrado). Universidade Federal de Rondônia, Porto Velho, Rondônia, Brasil.

PIACENTINI, A. L. S.; PEDRO FILHO, F.; ALMEIDA, F. M. (2015). Estudo epistemológico sobre práticas extra fiscais de gestão urbana sustentável. Inter Science Place Revista científica Internacional, $1(10)$.

PUNCH, K. (2011). Research Methods in Education (reprinted). London: SAGE.

VALE, S. M. L. R.; TEIXEIRA, M. B.; SANT'ANNA, J. C. O. (2015). Estilos gerenciais e eficácia administrativa na produção de café. Revista de Agronomia e Agronegócio, 4(4). Recuperado de http://www.rea.ufv.br/index.php/rea/ article/view/94/98.

VANZETTO, A. S. (2012). Análise das alternativas tecnológicas de desaguamento de lodos produzidos em estações de tratamento de esgoto (Dissertação de Mestrado). Universidade de Brasília, Brasília, Distrito Federal, Brasil.

YIN, R. K. (2010). Estudo de Caso-Planejamento e Métodos. São Paulo: Bookman. 